\title{
HUBUNGAN KECEMASAN DENGAN MINAT IBU MENJADI AKSEPTOR KONTRASEPSI METODE OPERATIF WANITA
}

\section{THE RELATION ANXIETY WITH MOTHER INTEREST BE CONTRACEPTION ACCEPTOR METHOD OF WOMEN OPERATIVE}

\author{
Eva Nur Azizah $^{1 *}$, Vide Bahtera Dinastiti ${ }^{2}$, Ratna Feti Wulandari ${ }^{3}$ \\ 1,2,3 STIKES Pamenang \\ *Korespondensi Penulis : evanaufa12019@gmail.com
}

\begin{abstract}
Abstrak
Kecemasan adalah kebingungan, kekhawatiran pada sesuatu yang akan terjadi, sedangkan minat adalah penerimaan akan suatu hubungan antara diri sendiri dengan sesuatu diluar diri, sehingga kecemasan yang ada masyarakat masih menjadi faktor yang mempengaruhi minat yang rendah terhadap kontrasepsi Metode Operatif Wanita. Tujuan penelitian penelitian ini untuk mengetahui ada tidaknya hubungan kecemasan dengan minat ibu menjadi akseptor kontrasepsi Metode Operatif Wanita.

Desain penelitian ini menggunakan analitik korelasional dengan pendekatan cross sectional. Sampel dalam penelitian ini adalah wanita dengan usia lebih dari 30 tahun, memiliki lebih dari 3 anak, dan memilih kontrasepsi jangka panjang. Teknik pengambilan sampel menggunakan Purposive sampling, dengan jumlah populasi 44 orang, sehingga sampel yang diambil berjumlah 30 responden. Untuk menilai kecemasan responden menggunakan HARS (Hamilton Anxienty Rating Scale) dan untuk menilai minat ibu menggunakan kuesioner dengan skala ordinal. Penelitian ini menggunakan Uji statistik Spearman Rank. Hasil penelitian dari 44 responden prosentase terbesar tingkat kecemasan ibu ada pada kriteria sedang sebanyak 21 responden (70 \%), dan minat ibu menjadi akseptor metode operatif wanita sebagian besar kriteria berminat 22 responden $(73,3 \%)$. Hasil uji statistika didapatkan angka probabilitas $(\mathrm{p})=0,000<0,05$ maka $\mathrm{H} 0$ ditolak dan $\mathrm{H} 1$ diterima, hal ini menunjukkan ada hubungan kecemasan dengan minat ibu menjadi akseptor kontrasepsi Metode Operatif Wanita. Nilai koefisien korelasi $r^{2}=0,701$, maka ada hubungan positif kuat antara kecemasan dengan minat ibu menjadi akseptor kontrasepsi Metode Operatif Wanita. berarti bahwa sebagian besar ibu yang merasakan kecemasan sedang maka ibu hanya berminat.

Berdasarkan hasil penelitian diatas, sebaiknya sebagai petugas kesehatan lebih banyak melakukan pendekatan ke masyarakat agar kecemasan dalam masyarakat dan minat ibu semakin tinggi.
\end{abstract}

Kata kunci : Kecemasan, Minat, Kontrasepsi

\begin{abstract}
Anxiety is confusion, worry about something that will happen, while interest is the acceptance of a relationship between yourself and something outside of yourself, so that the anxiety that exists in society is still a factor influencing low interest in contraception for the Women's Operative Method. The purpose of this research is to find out whether there is a relationship between anxiety and the interests of mothers to become contraceptive acceptors for Method of Women Operative.

The design of this study was correlational analytic with cross sectional approach. The sample in this study is women over 30 years old, had more than 3 children, and chose long-term contraception. The sampling technique uses purposive sampling, with a population of 44 people, so the samples taken amounted to 30 respondents. To assess respondents' anxiety using HARS (Hamilton Anxienty Rating Scale) and to assess maternal interest using a questionnaire. This study uses the Spearman Rank statistical test.

The results of the study of 44 respondents the greatest percentage of maternal anxiety levels are in the medium criteria of 21 respondents (70\%), and maternal interest in accepting the female operative method is mostly 22 respondents' interested criteria (73.3\%). Statistical test results obtained probability number $(p)=0,000<0.05$ then $\mathrm{HO}$ is rejected and $\mathrm{HI}$ is accepted, this shows
\end{abstract}


there is a relationship of anxiety with maternal interest in becoming Method Of Women Operatative contraceptive acceptors. Value correlation coefficient $r^{2}=0.701$, then there is a strong positive relationship between anxiety and maternal interest in becoming a contraceptive acceptor of Method Of Women Operatative means that most mothers who feel moderate anxiety are mothers only interested.

Based on the results of the research above, it is better as a health worker to approach the community more so that anxiety in the community and the higher interest of mothers.

Keywords: Anxiety, Interest, Contraception

\section{Pendahuluan}

Metode Operasi Wanita (MOW) merupakan metode keluarga berencana yang paling efektif, murah, aman, dan mempunyai nilai demografi yang tinggi. Tetapi masih ada faktor yang menyebabkan angka pengguna kontrasepsi Metode Operatif Wanita masih rendah $^{1}$. Berdasarkan hasil laporan profil kesehatan kabupaten Kediri tahun 2016, jumlah Wanita Usia Subur di kabupaten Kediri sebanyak 262.970 dengan cakupan peserta Keluarga Berencana aktif menurut rincian pemakaian kontrasepsi ialah sebanyak $59.185 \quad(30,2 \%)$ memakai Metode Kontrasepsi Jangka Panjang, sedangkan sebanyak $136.861 \quad(69,8 \%)$ memakai Non Metode Kontrasepsi Jangka Panjang ${ }^{2}$.

Metode kontrasepsi jangka panjang yaitu AKDR, Implant, dan MOW. Sasaran utama dari Metode Operatif Wanita adalah ibu dengan anak lebih dari 3 dan berusia lebih dari 35 tahun. MKJP Rendahnya angka penggunaan metode jangka panjang ini dikarenakan banyak faktor yang menjadi rumor tentang salah satunya kontrasepsi MOW. Kecemasan atas keterbatasan yang muncul seperti rasa sakit atau ketidaknyamanan yang timbul dalam jangka pendek setelah tindakan, resiko komplikasi kecil, pertimbangan dikarenakan sifat yang permanen pada kontrasepsi $\mathrm{MOW}^{3}$, rasa takut, kurangnya informasi pasien yang menyebabkan munculnya mitos tentang kontrasepsi MOW, rumor dalam masyarakat.

\section{Metode}

Desain penelitian ini menggunakan analitik korelasional dengan pendekatan cross sectional. Tempat Penelitian dilaksanakan di desa Bogem kecamatan Gurah kabupaten Kediri dan dilakukan pada 1-28 Februari 2017. Responden dalam penelitian ini adalah wanita dengan usia lebih dari 30 tahun, memiliki lebih dari 3 anak, dan memilih kontrasepsi jangka panjang. Teknik pengambilan sampel menggunakan Purposive sampling, dengan jumlah populasi 44 orang, sehingga sampel yang diambil berjumlah 30 responden. Untuk menilai kecemasan responden menggunakan HARS (Hamilton Anxienty Rating Scale) dan untuk menilai minat ibu menggunakan kuesioner. Uji statistik yang di gunakan dalam penelitian ini adalah uji Spearman Rank dengan tingkat kesalahan yang digunakan yaitu $5 \%$ atau 0,05 . Apabila $p$ value $\leq 0,05$ maka H0 di tolak, yang berarti ada hubungan yang signifikan antara variabel independen dan variabel dependen. Sedangkan untuk menguji adanya korelasi, kekuatan dan arah korelasi dilihat dari nilai $r^{2}$.

\section{Hasil Penelitian}

Hasil prosentase Kecemasan ibu Akseptor Kontrasepsi Metode Operatif Wanita (MOW)

Tabel 1 : Kecemasan ibu akseptor kontrasepsi Metode Operatif Wanita (MOW) di Desa Bogem Kabupaten Kediri Tahun 2017.

\begin{tabular}{|c|c|c|c|}
\hline No. & Kategori & Jumlah & $\%$ \\
\hline 1. & $\begin{array}{ll}\text { Tidak } & \text { ada } \\
\text { kecemasan } & \end{array}$ & 2 & 6,7 \\
\hline 2. & Kecemasan ringan & 5 & 16,6 \\
\hline 3. & Kecemasan sedang & 21 & 70 \\
\hline 4. & Kecemasan berat & 2 & 6,7 \\
\hline Jum & & 30 & 100 \\
\hline
\end{tabular}

Tabel 2 : Minat ibu menjadi akseptor kontrasepsi Metode Operatif Wanita (MOW) di Desa Bogem Kabupaten Kediri Tahun 2017

\begin{tabular}{llll}
\hline No. & Kategori & Jumlah & \% \\
\hline 1. & Sangat berminat & 8 & 26,7 \\
2. & Berminat & 22 & 73,3 \\
3. & Tidak berminat & 0 & 0 \\
\hline
\end{tabular}




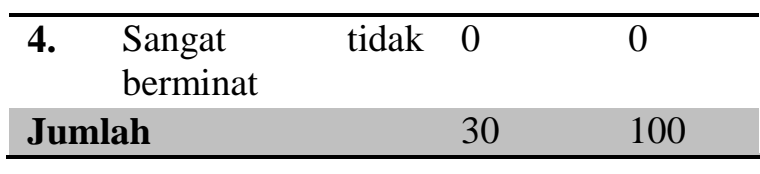

Tabel.3. Tabulasi silang Hubungan Kecemasan dengan minat ibu menjadi akseptor kontrasepsi Metode Operatif Wanita (MOW) di Desa Bogem Kecamatan Gurah Kabupaten Kediri Tahun 2017.

\begin{tabular}{|c|c|c|c|c|c|c|c|c|c|c|c|}
\hline \multirow[t]{2}{*}{ No } & \multirow{2}{*}{$\underbrace{\text { Minat }}_{\text {Kecemasan }}$} & \multicolumn{2}{|c|}{ Sangat beminat } & \multicolumn{2}{|c|}{ Beminat } & \multicolumn{2}{|c|}{$\begin{array}{c}\text { Tidak } \\
\text { berminat }\end{array}$} & \multicolumn{2}{|c|}{$\begin{array}{l}\text { Sangat } \\
\text { tidak } \\
\text { beminat }\end{array}$} & \multicolumn{2}{|c|}{ Jumlah } \\
\hline & & $\Sigma$ & $\%$ & $\Sigma$ & $\%$ & $\Sigma$ & $\%$ & $\Sigma$ & $\%$ & $\Sigma$ & $\%$ \\
\hline 1. & Tidak ada kecemasan & 2 & 100 & 0 & 0 & 0 & 0 & 0 & 0 & 2 & 100 \\
\hline 2. & Kecemasan ringan & 4 & 80 & 1 & 20 & 0 & 0 & 0 & 0 & 5 & 100 \\
\hline 3. & Kecemasan sedang & 2 & 9,5 & 19 & 90,5 & 0 & 0 & 0 & 0 & 21 & 100 \\
\hline 4. & Kecemasan berat & 0 & 0 & 2 & 100 & 0 & 0 & 0 & 0 & 2 & 100 \\
\hline Jun & & 10 & 33,3 & 20 & 66,7 & 0 & 0 & 0 & 0 & 30 & 100 \\
\hline
\end{tabular}

Berdasarkan tabel di atas dapat diketahui bahwa dari 30 responden yang tidak mengalami kecemasan mayoritas sangat berminat $6,7 \%$. Responden yang mengalami kecemasan sedang lebih dari sebagian berminat $63,3 \%$. Responden yang mengalami kecemasan berat mayoritas berminat $6,7 \%$.

Tabel 4. Hasil analisis menggunakan korelasi Spearman :

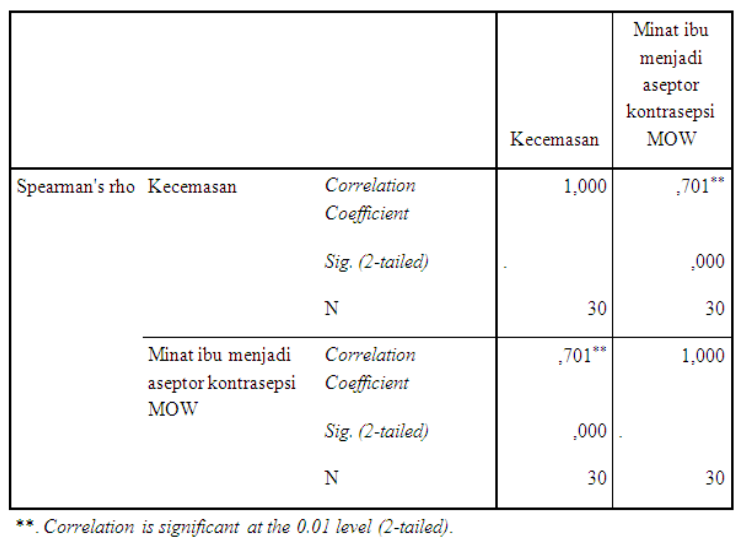

Dari hasil uji statistika dengan korelasi Spearman Rank, didapatkan angka probabilitas $(\mathrm{p})=0,000<0,05$ maka $\mathrm{H} 0$ ditolak dan H1 diterima, hal ini menunjukkan ada hubungan kecemasan dengan minat ibu menjadi akseptor kontrasepsi MOW.

\section{Pembahasan}

Hasil penelitian yang dilakukan di desa Bogem kecamatan Gurah kabupaten Kediri dari 44 responden prosentase terbesar tingkat kecemasan ibu ada pada kriteria sedang sebanyak 21 responden (70\%). Kecemasan ibu menggunakan kontrasepsi MOW dipengaruhi oleh beberapa faktor yaitu umur, pendidikan, pekerjaan. Semakin cukup umur tingkat kematangan seseorang akan lebih meningkat dam berfikir, maka akan lebih mampu mengatasi masalah-masalah yang dihadapi termasuk di dalam hal mengantisipasi kecemasan dibandingkan mereka yang lebih muda. Hal ini sebagai akibat dari pengalaman dan kematangan jiwa yang ditunjukkan dengan hasil pengelompokan umur responden yang berumur $<50$ cenderung tidak mengalami kecemasan.

Begitu juga tingkat pendidikan seseorang makin tinggi, makin mudah juga menerima informasi sehingga semakin banyak pula pengetahuan di dalam mengantisipasi kecemasan, mampu mengatasi kecemasan dibandingkan mereka yang berpendidikan rendah. Dari responden yang mengalami kecemasan sedang sebagian besar dari pendidikan SD.

Kecemasan adalah respon emosi tanpa obyek yang spesifik yang secara subyektif dialami dan dikomunikasikan secara interpersonal. Kecemasan adalah kebingungan, kekhawatiran pada sesuatu yang akan terjadi dengan penyebab yang tidak jelas dihubungkan dengan perasaan tidak menentu dan tidak berdaya demikian juga dengan semakin banyaknya informasi tentang kecemasan yang diterima serta cara mengatasinya, maka akan mampu meningkatkan respon seseorang dalam mengantisipasi kecemasan. Dimana lingkungan sekitar tinggal mempengaruhi tentang cara berfikir diri sendiri dan orang lain. Hal ini bisa saja disebabkan pengaruh pengalaman dengan keluarga, sahabat, rekan kerja. Kecemasan dapat timbul jika kita merasa tidaknyaman dengan lingkungan kita.

Minat ibu menjadi akseptor metode operatif wanita sebagian besar kriteria berminat 22 responden $(73,3 \%)$. Sebagian besar responden yang diteliti mengalami kecemasan sedang hal ini merupakan sikap hasil adanya ketakutan dari responden untuk menjadi akseptor kontrasepsi MOW 
dikarenakan tindakan pembedahan kecil, tetapi di sini sebagian besar responden berminat.

Minat adalah aspek psikologis pada seseorang atau rasa tertarik, berusaha ingin tahu, berusaha mengikuti, bersedia berkorban baik waktu, biaya dan tenaga. Minat juga diartikan kecenderungan hati yang tinggi terhadap sesuatu, minat bukan bawaan dari lahir, melainkan dapat dipengaruhi oleh bakat. Minat diciptakan atau dibina agar tumbuh dan terasa sehingga menjadi kebiasaan.

Hasil uji statistika didapatkan angka probabilitas $(\mathrm{p})=0,000<0,05$ maka $\mathrm{H} 0$ ditolak dan $\mathrm{H} 1$ diterima, hal ini menunjukkan ada hubungan kecemasan dengan minat ibu menjadi akseptor kontrasepsi Metode Operatif Wanita. Nilai koefisien korelasi $r^{2}=0,701$, maka ada hubungan positif kuat antara kecemasan dengan minat ibu menjadi akseptor kontrasepsi Metode Operatif Wanita (MOW). berarti bahwa sebagian besar ibu yang merasakan kecemasan sedang maka ibu hanya berminat.

Hasil analisa data kecemasan dan minat responden terhadap kontrasepsi Metode Operatif Wanita (MOW) sebagian besar berminat. Hal ini dikarenakan para responden mengetahui bahwa Metode Operasi Wanita (MOW) merupakan metode keluarga berencana yang paling efektif, murah, aman, dan mempunyai nilai demografi yang tinggi. Tetapi masih ada faktor yang menyebabkan angka pengguna kontrasepsi Metode Operatif Wanita (MOW) masih rendah ${ }^{1}$. Kecemasan adalah respon emosi tanpa objek yang spesifik yang secara subyektif dialami dan dikomunikasikan secara interpersonal. Kecemasan adalah kebingungan, kekhawatiran pada sesuatu yang akan terjadi dengan penyebab yang tidak jelas dihubungkan dengan perasaan tidak menentu dan tidak berdaya $^{5}$. Dari munculnya kecemasan yang ada masyarakat masih memiliki minat yang rendah terhadap kontrasepsi Metode Operatif Wanita (MOW) dikarenakan banyak faktor yang menjadi rumor tentang kontrasepsi Metode Operatif Wanita (MOW). Hal ini sejalan dengan penelitian Septalia bahwa ada pendapat agama yang mengharamkan penggunaan Metode Operasi Wanita (MOW) dan Metode Operasi Pria (MOP). Selain itu juga dipengaruhi oleh pengetahuan dari calon akseptor Keluarga Berencana ${ }^{5}$, pada penelitian Forcepta mengatakan bahwa salah satu factor yang memepengaruhi ibu atau pasangan usia subur memilih penggunaan Metode Operasi Wanita (MOW) yaitu faktor pengetahuan ${ }^{6,7}$. Pengetahuan ini juga dipengaruhi banyak hal yaitu karena pengalaman, pendidikan, keyakinan, bahkan fasilitas sebagai sumber informasi yang di dapat $^{8}$. Selain itu juga dukungan dari suami juga mempengaruhi kesiapan ibu, hal ini sesuai dengan penelitian yang dilakukan Muniroh'. Dukungan suami dalam memilih kontrasepsi merupakan bentuk nyata dari tanggung jawab kepala rumah tangga ${ }^{10}$. Dukungan ini juga merupakam factor sosiogenik untuk meningkatkan motivasi seseorang untuk melakukan sesuatu ${ }^{11}$.

Untuk mengatasi rendahnya minat masyarakat dalam menerapkan metode kontrasepsi Metode Operatif Wanita (MOW) seperti pemberian pengertian pada ibu secara lengkap tentang kontrasepsi Metode Operatif Wanita (MOW) dan manfaat dari berkeluarga berencana yang berguna untuk mengatur jarak persalinan dan jumlah anggota keluarga supaya dapat tercapai tujuan keluarga kecil bahagia dan sejahtera ${ }^{12}$.

\section{Kesimpulan}

Keadaan cemas dari seorang akseptor Metode Operatif Wanita (MOW) akan mempengaruhi minat nya dalam memilih kontrasepsi Metode Operatif Wanita (MOW). Terutama kecemasan seseorang dipengaruhi oleh pengetahuan dan pengaruh lingkungan sekitar. Lingkungan sekitar bisa juga dipengaruhi oleh dukungan dari suami.

\section{Saran}

Saran dari peneliti perlu peningkatan KIE (Komunikasi, Informasi, dan Edukasi) kepada Wanita Pasangan Usia Subur tentang kontrasepsi, terutama kontrasepsi jangka panjang. Dapat dijadikan sebagai masukan untuk mengetahui bagaimana tingkat kecemasan dan minat responden terhadap kontrasepsi MOW, serta dapat dijadikan bahan agar para responden dapat lebih aktif mendapatkan informasi tentang kontrasepsi MOW

\section{Ucapan Terima Kasih}

Peneliti mengucapkan terima kasih kepada Direktur Akademi Kebidanan Pamenang dan Lembaga Penelitian Pengabdian Masyarakat Akademi Kebidanan Pamenang serta seluruh warga desa Bogem 
kecamatan Gurah kabupaten Kediri yang telah mendukung penelitian ini.

\section{Daftar Pustaka}

Manuaba. Ilmu Kebidanan, Penyakit Kandungan, dan KB untuk pendidikan Bidan. Jakarta : EGC; 2010.

Dinas Kesehatan Kabupaten Kediri. 2016. Profil Kesehatan Kabupaten Kediri

Yanti, N.H., Revida, Erika, \& Asfriyati, 2013. Pengaruh Budaya Akseptor KB Terhadap Penggunaan Kontrasepsi IUD di Kecamatan Pantai Labu Kabupaten Deli Serdang. Jurnal Darma Agung: 1-15.

Agustin D, Siwi RPY, Sugiyanto. Faktor-faktor yang berpengaruh terhadap rendahnya minat dalam menggunakan kontrasepsi MOW pada PUS di Desa Tanon Kecamatan Papar Kabupaten Kediri. 2013: 2(2);1-7.

Septalia, Rendys, \& Puspitasai, Nunik, 2016. Faktor yang mempengaruhi Pemilihan Metode Kontrasepsi. Jurnal Biometrika dan Kependudukan. Vol 5 No 2 Nomor 91-98. https://ejournal.unair.ac.id/JBK/article/view/5828/373 1

Forcepta, Chania, \& Rodiani, 2017. Faktor-faktor Penggunaan Alat Kontrasepsi Medis Operasi Wanita pada Pasangan Wanita Usia Subur. Medical Journal of Lampung University. Vol6, No.1, 11-17. http://juke.kedokteran.unila.ac.id/index.php/m ajority/article/view/1523/1481

Diah Atmarina Yuliani. 2019. Hubungan Paritas Dengan Pengetahuan Pasangan Usia Subur (PUS) Dalam Pemilihan Kontrasepsi Metode Operasi Wanita (MOW). Jurnal Ilmiah Rekam Medis dan Informatika Kesehatan, Vol 9 No 1: http://ojs.udb.ac.id/index.php/infokes/article/v iew/704/638
Zulfajri Rahman, Firdaus J. Kunoli, Finta Amalinda. The Factors Related To The Application Of Contraception Method Of Women Operation (MOW). PROMOTIF: Jurnal Kesehatan Masyarakat. Volume 7, Nomor $2 . \quad 153-157$. https://jurnal.unismuhpalu.ac.id/index.php/PJ KM/article/viewFile/89/81

Muniroh, Ismi Dita; Lutviatin, Novia; Istiaji, Erdi. Dukungan Sosial Suami Terhadap Istri untuk Menggunakan Alat Kontrasepsi Medis Operasi Wanita (MOW) (Studi Kualitatif pada Pasangan Usia Subur Unmet Need di Kecamatan Puger Kabupaten Jember) Husband's Social Support on Their Wive to Use Contraception . Pustaka Kesehatan, [S.1.], v. 2, n. 1, p. 66-71, jan. 2014. ISSN 2355$178 X$. Available at: $<$ https://jurnal.unej.ac.id/index.php/JPK/arti cle/view/598>.

Fitra Sawiyya Sufiati, Drs. H. Mardj,Ismael Saleh. 2014. Faktor- Faktor Yang Berhubungan dengan Pemilihan Metode Kontrasepsi Tubektomi Pada Pasangan Usia Subur. Jurnal Mahasiswa dan Peneliti Kesehatan -JuMantik. http://openjurnal.unmuhpnk.ac.id/index.php/JJ UM/article/viewFile/159/133

Rafidah, Ida dan Arief Wibowo. 2012. Pengaruh Dukungan Suami Terhadap Kepatuhan Akseptor Melakukan KB Suntik. Jurnal Biometrika dan Kependudukan. Volume 1 (Nomor1). Fakultas Kesehatan Masyarakat Universitas Airlangga.

Herdyanae., \& Sulisi. F. (2019). Perbedaan Pengetahuan Wanita Pus Tentang Metode Kontrasepsi Mow Sebelum Dan Sesudah Penyuluhan (Di RT 02 RW 02 Desa Banyakan Kecamatan Banyakan Kabupaten Kediri ). JURNAL KEBIDANAN, 6(1), 56-65. https://doi.org/10.35890/jkdh.v6i1. 